\title{
A retrospective study of antibiotic resistance patterns of bacterial pathogens isolated from patients in two Lebanese hospitals for two consecutive years (2018 and 2019)
}

\author{
${ }^{1}$ Sakr, S., ${ }^{2}$ Abboud, M., ${ }^{3}$ Tawbeh, K., ${ }^{1}$ Hamam, B., and ${ }^{*}$ Sheet, I. \\ ${ }^{1}$ Department of Biological and Chemical Sciences, School of Arts and Sciences, \\ Lebanese International University, Lebanon \\ ${ }^{2}$ Haroun Hospital, Beirut, Lebanon \\ ${ }^{3}$ Department of Mathematics and Physics, School of Arts and Sciences, \\ Lebanese International University, Lebanon \\ *Correspondence to: imtithal.sheet@liu.edu.Ib
}

\begin{abstract}
:
Background: Misuse of antibiotics is the leading factor promoting emergence of bacterial resistance, a situation that has become a serious public health challenge. Among the leading bacteria that have developed resistance to antibiotics are Staphylococcus aureus, Enterococcus faecalis, Escherichia coli, Klebsiella pneumoniae and Pseudomonas aeruginosa, which have caused infections in patients, resulting in considerable mortality. The objective of this retrospective study was to assess antibiotic resistance rates of bacterial pathogens isolated from clinical specimens in two Lebanese hospitals between the years 2018 and 2019.

Methodology: Bacteria isolated from routine clinical specimens collected from hospitalized patients in two hospitals, Haroun and Bekaa, in Lebanon for 2018 and 2019, were analyzed. Bacteria isolation and identification were carried out at the laboratory of each hospital using conventional microbiological methods. Antimicrobial susceptibility testings (AST) of each bacterial isolate to antibiotics were performed by the disc diffusion test and interpreted using EUCAST, CLSI or WHO/AST guidelines. Comparisons of the mean resistance rates of each isolate to individual antibiotics by year of isolation were done using the Z-test and $p<0.05$ was considered statistically significant.

Results: There were a total of 1698 bacteria isolates recovered from hospitalized patients in the two hospitals for 2018 and 2019, of which 87.5\% were Gram-negative and 12.5\% were Gram-positive bacteria. The most frequent among the Gram-negative isolates was E. coli $(66.1 \%)$ followed by $P$. aeruginosa $(13.3 \%), K$. pneumoniae $(7.7 \%)$, Proteus mirabilis (6.7\%) and Enterobacter spp (6.3\%), while coagulase positive staphylococci CoPS (68.4\%) and $E$. faecalis (31.6\%) were the two Gram positive isolates. Of the Gram-negative isolates over the two-year period, $72.2 \%$ of $E$. coli and $76.3 \%$ of $K$. pneumoniae were resistant to ceftazidime, $93 \%$ of $P$. mirabilis to colistin, and $98 \%$ of Enterobacter to cefoxitin, but low resistance rates were demonstrated by $E$. coli to imipenem (1\%), K. pneumoniae to tigecycline and amikacin $(0.9 \%), P$. mirabilis to imipinem $(2 \%)$, and Enterobacter to amikacin, ertapenem and tigecycline (3\%). Resistance of $P$. aeruginosa varied between $2 \%$ to colistin and $24 \%$ to levofloxacin. For the Grampositive bacteria, $79.1 \%$ of $E$. faecalis were resistant to erythromycin while $70 \%$ of CoPS were resistant to cefoxitin, but no isolate was resistant $(0 \%)$ to linezolid, and only $1 \%$ to teicoplanin. Except for Enterobacter spp that showed significant increase in resistance rates (by 250\%) to piperacillin/tazobactam in 2019 over 2018, resistance rates of other Gram-negative isolates significantly decreased in 2019 compared to $2018(p<0.05)$. For the Gram-positive isolates, resistance rates to many antibiotics tested significantly increased (by a factor of $36.5-2569 \%$ ) in 2019 compared to 2018 among E. faecalis isolates in contrast to the rates for CoPS which significantly decreased by 16.7 - $65.7 \%$, except for penicillin $\mathrm{G}$ which increased by a factor of $123 \%$.

Conclusion: Overuse and misuse of antibiotics, which is possible because of the easy access of the populace to these drugs, is a leading factor contributing to the high antibiotic resistance rates in this study. There is need to promote awareness of antimicrobial resistance in Lebanon among students especially in non-health related majors and enactment of govermental policy that will limit access to antibiotics.
\end{abstract}

Keywords: antibiotic resistance; changing pattern; hospitalized patients; retrospective 


\title{
Une étude rétrospective des profils de résistance aux antibiotiques de pathogènes bactériens isolés de patients dans deux hôpitaux libanais pendant deux années consécutives (2018 et 2019)
}

\author{
${ }^{1}$ Sakr, S., ${ }^{2}$ Abboud, M., ${ }^{3}$ Tawbeh, K., ${ }^{1}$ Hamam, B., et $* 1$ Sheet, I. \\ ${ }^{1}$ Département des Sciences Biologiques et Chimiques, École des Arts et des Sciences, \\ Université internationale Libanaise, Liban \\ ${ }^{2}$ Haroun Hospital, Beyrouth, Liban \\ ${ }^{3}$ Département de Mathématiques et de Physique, École des Arts et des Sciences, \\ Université Internationale Libanaise, Liban \\ *Correspondance à: imtithal.sheet@liu.edu.lb
}

\begin{abstract}
Abstrait:
Contexte: La mauvaise utilisation des antibiotiques est le principal facteur favorisant l'émergence de la résistance bactérienne, une situation qui est devenue un sérieux défi de santé publique. Parmi les principales bactéries qui ont développé une résistance aux antibiotiques figurent Staphylococcus aureus, Enterococcus faecalis, Escherichia coli, Klebsiella pneumoniae et Pseudomonas aeruginosa, qui ont provoqué des infections chez les patients, entraînant une mortalité considérable. L'objectif de cette étude rétrospective est d'évaluer les taux de résistance aux antibiotiques des pathogènes bactériens isolés à partir d'échantillons cliniques dans deux hôpitaux Libanais entre les années 2018 et 2019.

Méthodologie: Les isolats bactériens prélevés sur des patients hospitalisés dans deux hôpitaux, Haroun et Bekaa, au Liban pour 2018 et 2019, ont été analysés. L'isolement et l'identification des bactéries ont été réalisés au laboratoire de chaque hôpital en utilisant des méthodes microbiologiques conventionnelles. Les tests de sensibilité aux antimicrobiens (AST) de chaque isolat bactérien aux antibiotiques ont été réalisés par le test de diffusion sur disque et interprétés selon les directives EUCAST, CLSI ou WHO/AST. Des comparaisons des taux moyens de résistance de chaque isolat à des antibiotiques individuels par année d'isolement ont été effectuées à l'aide du test $Z$ et $p<0,05$ a été considéré comme statistiquement significatif.

Résultats: Il y a eu un total de 1698 isolats de bactéries récupérés de patients hospitalisés dans les deux hôpitaux durant 2018 et 2019, dont 87,5\% étaient à Gram négatif et $12,5 \%$ étaient des bactéries à Gram positif. Les isolats à Gram négatif les plus fréquents étaient $E$. coli $(66,1 \%)$, suivis de $P$. aeruginosa $(13,3 \%), K$. pneumoniae (7,7\%), Proteus mirabilis $(6,7 \%)$ et Enterobacter spp $(6,3 \%)$, tandis que les staphylocoques à coagulase positive CoPS $(68,4 \%)$ et $E$. faecalis $(31,6 \%)$ étaient les deux isolats Gram positifs. Parmi les isolats à Gram négatif sur la période de deux ans, $72,2 \%$ d' $E$. coli et $76,3 \%$ de $K$. pneumoniae étaient résistants à la ceftazidime, $93 \%$ de $P$. mirabilis à la colistine et $98 \%$ d'Enterobacter à la céfoxitine, mais faible les taux de résistance ont été démontrés par $E$. coli à l'imipénem $(1 \%), K$. pneumoniae à la tigécycline et à l'amikacine $(0,9 \%), P$. mirabilis à l'imipinem (2\%) et Enterobacter à l'amikacine, à l'ertapénem et à la tigécycline (3\%). La résistance de $P$. aeruginosa variait entre $2 \%$ à la colistine et $24 \%$ à la lévofloxacine. Pour les bactéries Gram positif, $79,1 \%$ des E. faecalis étaient résistantes à l'érythromycine tandis que $70 \%$ des CoPS étaient résistantes au céfoxitin, mais aucun isolat n'était résistant (0\%) au linézolide et seulement $1 \%$ à la teicoplanine. À l'exception d'Enterobacter spp qui ont montré une augmentation significative des taux de résistance (de 250\%) à la pipéracilline/tazobactam en 2019 par rapport à 2018, les taux de résistance des autres isolats à Gram négatif ont considérablement diminué en 2019 par rapport à $2018(p<0,05)$. Pour les isolats Gram-positifs, les taux de résistance à de nombreux antibiotiques testés ont augmenté de manière significative (d'un facteur de 36,5 à 2569\%) en 2019 par rapport à 2018 parmi les isolats d'E. faecalis contrairement aux taux de CoPS qui ont significativement diminué de 16,7 à $65,7 \%$, à l'exception de la pénicilline $\mathrm{G}$ qui a augmenté d'un facteur de $123 \%$.

Conclusion: la surutilisation et la mauvaise utilisation des antibiotiques, ce qui est possible en raison de l'accès facile de la population à ces médicaments, est l'un des principaux facteurs contribuant aux taux élevés de résistance aux antibiotiques dans cette étude. Il est nécessaire de promouvoir la sensibilisation à la résistance aux antimicrobiens au Liban parmi les étudiants, en particulier dans les spécialisations non liées à la santé, et la promulgation d'une politique gouvernementale qui limitera l'accès non contrôlé aux antibiotiques.
\end{abstract}

Mots clés: résistance aux antibiotiques; changement de modèle; patients hospitalisés; rétrospective

\section{Introduction:}

Antimicrobial resistance (AMR) occurs when the drug loses its ability to effectively inhibit bacterial growth (1). In the developing countries, almost all antibiotics are available and can be purchased without medical prescription, which is one of the main factor underlying emergence of antimicrobial resistance (1). AMR is creating a serious global public health threat (2). In 2017, 12 bacterial species were identified by the World Health Organisation (WHO) to represent a threat to human health with majority being Gram negative bacteria (GNB), such as Acinetobacter, Pseudomonas aeruginosa, Enterobacteriaceae, Helicobacter pylori, Salmonella spp., Neisseria gonorrhoeae and Shigella spp (3). The Enterobacteriaceae are 
now globally reported to be resistant to carbapenems, third generation cephalosporins, and colistin (3).

Recently, the European Center for Disease Prevention and Control (ECDC) reported that GNBs are responsible for more than 500,000 infections and more than 24,600 deaths in Europe in just one year (4). The WHO press release highlights the real threat of GNBs which have developed remarkable mechanisms enabling them to resist antibiotic actions (5). In the United States and European countries, the number of deaths due to antibiotic resistance in Staphylococcus aureus, Escherichia coli, Enterococcus faecium, Klebsiella pneumoniae and $P$. aeruginosa was estimated to be 50,000 yearly (6). Laws et al., (7) reported that between 2011 and 2014, the percentage of $K$. pneumoniae and $E$. coli infections resistant to fluoroquinolones, third-generation cephalosporins or aminoglycosides, as well as combined resistance to all three antibiotic groups, significantly increased in Europe.

The WHO global report on antimicrobial resistance indicates that resistance of common bacteria has reached alarming levels in many African countries, as over $50 \%$ of $E$. coli and Klebseilla isolates were reported to be resistant to the third generation cephalosporins and carbapenems (5). Mouiche et al., (8) also reported in Cameroon in 2019 high levels of resistance of $E$. coli, Klebsiella $\mathrm{sp}, S$. aureus, $P$. aeroginosa, Enterobacter spp, and Proteus spp to tetracycline, amoxicillin, nalidixic acid, ampicillin and trimethoprim but low levels of resistance to gentamicin, ceftriaxone and ciprofloxacin. Ahmed et al., (9) reported in 2019 that the prevalence of $E$. coli resistance to most antibiotics such as amoxicillin, amoxicillin/clavulanic acid, ampicillin and ciprofloxacin was very high in Bangladesh. Resistance patterns of microbes vary from country to country, large hospital to small hospital, and from hospital to the community (10). Among these increasingly antimicrobial resistance infections are methicillin resistant S. aureus (MRSA), which have become prevalent in many countries, including the USA, European countries, South America and Asia (11). Another growing threat worldwide is $E$. coli and $K$. pneumoniae harboring extended-spectrum beta lactamases (ESBL) (12).

In the past few years, in the Middle East, the frequency of drug-resistant bacteria isolates has been increasing in different hospitals as confirmed by the WHO (13). Over 700,000 deaths are reported yearly due to AMR, and in the absence of appropriate control and preventive measures, AMR is projected to become one of the main causes of death among hospitalized and non-hospitalized patients in the developed countries (14). In the Mediterranean countries, many studies have reported emergence of bacterial resistance mechanisms such as ESBL, AmpC and carbapenemases in Gram negative bacteria, methicillin and vancomycin resistance in Gram positive organisms, and penicillin resistance in Streptococcus pneumoniae (15).

In Lebanon, as in other developing countries, AMR is responsible for significant morbidity and mortality in different hospitals (16). The most important factor leading to the emergence of AMR is the uncontrolled or inappropriate use (misuse and overuse) of antimicrobial drugs (17). This is mainly due to incorrect diagnosis and missuse of antimicrobials due either to an inappropriate prescription or poor compliance (18). Sakr et al., (19) reported in 2020 that in order to control the growing problem of antibiotic resistance in Lebanon, there is an urgent need for awareness campaigns on appropriate use of antibiotics in parallel with rigorous surveillance system for antimicrobial use and resistance.

In a cross-sectional study conducted by Moghnieh et al., (20) on antimicrobial susceptibility pattern of bacterial isolates from hospitalized patients in 13 Lebanese hospitals over two consecutive years (2015 - 2016), an overall decrease in susceptibility of bacterial isolates to different antibiotics among clinical GNB and GPB involved in various infections was reported. To the best our knowledge, there are no reports of antibiotic resistance rates of isolated strains in Lebanese hospitals during the last two years (2018 and 2019). The objective of this current study therefore is to investigate the changing pattern of antibiotic resistance of bacteria pathogens isolated from hospitalized patients with clinical infections in two Lebanese hospitals over this period.

\section{Materials and method:}

\section{Study setting and population}

This retrospective study was conducted in two hospitals (in Haroun and Bekaa) in Lebanon with about $70 \%$ of bacterial isolates from hospitalized patients in Internal Medicine department and 30\% from patients in Surgical and Outpatient deparments, Intensive Care Unit (ICU) and intubated patients in Coronary Care Unit.

\section{Specimen types}

Bacterial isolates were recovered from routine clinical specimens such as urine, sputum, tracheal aspirates, pus, abscess, blood, wounds and rectal specimens, which were 
collected from patients of different age groups and gender.

\section{Culture isolation and identification of bacterial isolates from specimens}

All clinical samples were routinely cultured in the laboratory of the two hospitals on standard agar media appropriate for each specimen, and these included Blood agar, Salmonella Shigella (SS) agar, MacConkey agar, Columbia agar, Chocolate agar, Schaedler agar, and Thiosulfate Citrate Bile salt Sucrose (TCBS) agar, using standard microbiological methods.

\section{Antibiotic susceptibility testing}

The antibiotic susceptibility testings (AST) of the isolates were routinely performed against anti-bacterial agents (as shown in Table 1 ) by the disc diffusion method, and zone diameters of inhibition interpreted according to the EUCAST/2019, CLSI/2018 or WHO/MOH/ SOP susceptibility testing/2018 guidelines. The ASTs were performed using Muller-Hinton (MH) agar except for streptococcal (enterococcal) isolates which were performed on $\mathrm{MH}$ media supplemented with blood.
The discs contents used for the AST were; trimetropim/sulfamethoxazole $1.25 / 23.75 \mu \mathrm{g}$, ciprofloxacin $5 \mu \mathrm{g}$, ofloxacin $5 \mu \mathrm{g}$, pefloxacin $5 \mu \mathrm{g}$, penicillin $\mathrm{G} 10 \mu \mathrm{g}$, imipenem $10 \mu \mathrm{g}$, gentamicin $10 \mu \mathrm{g}$, colistin $10 \mu \mathrm{g}$, tigecycline $15 \mu \mathrm{g}$, amoxicillin /clavulinic acid 20/10 $\mathrm{g}$, piperacillin/tazobactam $100 / 10 \mu \mathrm{g}$, cefepime $30 \mu \mathrm{g}$, cefoxitin 30 $\mu \mathrm{g}$, cefotaxime $30 \mu \mathrm{g}$, cefuroxime $30 \mu \mathrm{g}$, cefotaxime $30 \mu \mathrm{g}$, ceftazidime $30 \mu \mathrm{g}$, amikacin 30 $\mu \mathrm{g}$, clindamycin $30 \mu \mathrm{g}$, erythromycin $30 \mu \mathrm{g}$, vancomycin $30 \mu \mathrm{g}$, teicoplanin $30 \mu \mathrm{g}$, fosfomycin $300 \mu \mathrm{g}$, and nitrofurantoin $300 \mu \mathrm{g}$.

\section{Statistical analysis of data}

The bacterial identification and susceptibility data were tabulated in Excel spreadsheets. The resistance rates to individual antibiotic were calculated for every bacterial isolate by year of isolation. The mean percentage resistance of each isolate to all tested antibiotics were also calculated. Yearly comparisons were performed using Z-test after checking the applicability conditions. When comparing results from the two different years, $p<0.05$ was considered statistically significant if at least one value was different from the other.

Table 1: Antibacterial agents with their respective classes used in this study

\begin{tabular}{|c|c|c|}
\hline Antibacterial drug class & Antibacterial drug & Disc content $(\boldsymbol{\mu g})$ \\
\hline Aminoglycoside & $\begin{array}{c}\text { Gentamicin } \\
\text { Amikacin }\end{array}$ & $\begin{array}{l}10 \\
30\end{array}$ \\
\hline Glycopeptide & $\begin{array}{c}\text { Amoxicillin/clavulanic acid } \\
\text { Cefepime } \\
\text { Cefotaxime } \\
\text { Cefoxitin } \\
\text { Ceftazidime } \\
\text { Ceftriaxone } \\
\text { Cefuroxime } \\
\text { Imipinem } \\
\text { Piperacillin/tazobactam } \\
\text { Penicillin G } \\
\text { Vancomycin } \\
\text { Teicoplanin }\end{array}$ & $\begin{array}{c}20 / 10 \\
30 \\
30 \\
30 \\
30 \\
30 \\
30 \\
10 \\
100 / 10 \\
10 \\
30 \\
30\end{array}$ \\
\hline $\begin{array}{l}\text { Fluoroquinolone } \\
\text { Fosfomycin }\end{array}$ & $\begin{array}{l}\text { Ciprofloxacin } \\
\text { Ofloxacin } \\
\text { Pefloxacin } \\
\text { Fosfomycin }\end{array}$ & $\begin{array}{c}5 \\
5 \\
5 \\
300\end{array}$ \\
\hline $\begin{array}{l}\text { Inhibitor of folate pathway } \\
\text { Lincosomide } \\
\text { Macrolide } \\
\text { Nitrofuran }\end{array}$ & $\begin{array}{c}\text { Sulfamethoxazole/trimethoprim } \\
\text { Clindamycin } \\
\text { Erythromycin } \\
\text { Nitrofurantion }\end{array}$ & $\begin{array}{c}1.25 / 23.75 \\
30 \\
30 \\
300\end{array}$ \\
\hline $\begin{array}{l}\text { Oxazolidinone } \\
\text { Polymyxin E } \\
\text { Glycycyline }\end{array}$ & $\begin{array}{l}\text { Linezolid } \\
\text { Colistin } \\
\text { Tigecycline }\end{array}$ & $\begin{array}{l}30 \\
10 \\
15\end{array}$ \\
\hline
\end{tabular}




\section{Ethical consideration}

The study was reviewed and approved by the Lebanese International University Institutional Review Board (IRB) ethical committee (Reference LIUIRB-200305-SS2). All collected data were purely based on microorganisms, and there was no need for a written informed consent as all the patients were anonymous and no personal information was used in the study.

\section{Results:}

A total of 1698 bacterial isolates from patients with clinical infections in the two hospitals were recovered in the year 2018 and 2019. As shown in Table 2, there were 1486 (87.7\%) Gram-negative bacterial isolates and $212(12.3 \%)$ Gram-positive isolates (12.3\%).
The Gram-negative isolates are distributed as follows; 982 E. coli (66.1\%), $114 \mathrm{~K}$. pneumoniae (7.7\%), 99 P. mirabilis (6.7\%), 198 P. aeruginosa (13.3\%) and 93 Enterobacter sp. (6.3\%). Among the Gram-positive isolates; 67 (31.6\%) were E. faecalis and 145 (67.4\%) were coagulase positive staphylococci (mainly $S$. aureus).

As presented in Table 3a, a total of 982 $E$. coli isolates were recovered; 465 isolates in 2018 and 517 isolates in 2019 . Their resistance pattern to 18 antibiotics showed that between $44 \%$ and $68 \%$ isolates were resistant to amoxicillin/clavulanic acid, cefotaxime, ceftazidime, ceftriaxone, cefuroxime, ciprofloxacin, colistin, pefloxacin and sulfamethoxazole/ trimethoprim. However, compared to 2018, the resistance rate of the isolates in 2019 to cefoxitin, ceftazidime, colistin, fosfomycin,

Table 2: Frequency of bacterial pathogens isolated from patients in two Lebanese hospitals (2018-2019)

\begin{tabular}{cc}
\hline Bacterial isolates & Number (\%) \\
\hline Gram-negative isolates & $\mathbf{1 4 8 6 ( 8 7 . 5 )}$ \\
Escherichia coli & $982(66.1)$ \\
Klebsiella pneumoniae & $114(7.7)$ \\
Proteus mirabilis & $99(6.7)$ \\
Pseudomonas aeruginosa & $198(13.3)$ \\
Enterobacter sp. & $93(6.3)$ \\
Enterococcus faecalis & $\mathbf{2 1 2 ( 1 2 . 5 )}$ \\
Coagulase positive staphylococci & $67(31.6)$ \\
Gram positive isolates & $145(68.4)$ \\
\hline
\end{tabular}

Table 3a: Resistance rates of Gram-negative isolates in 2018 and 2019: Escherichia coli

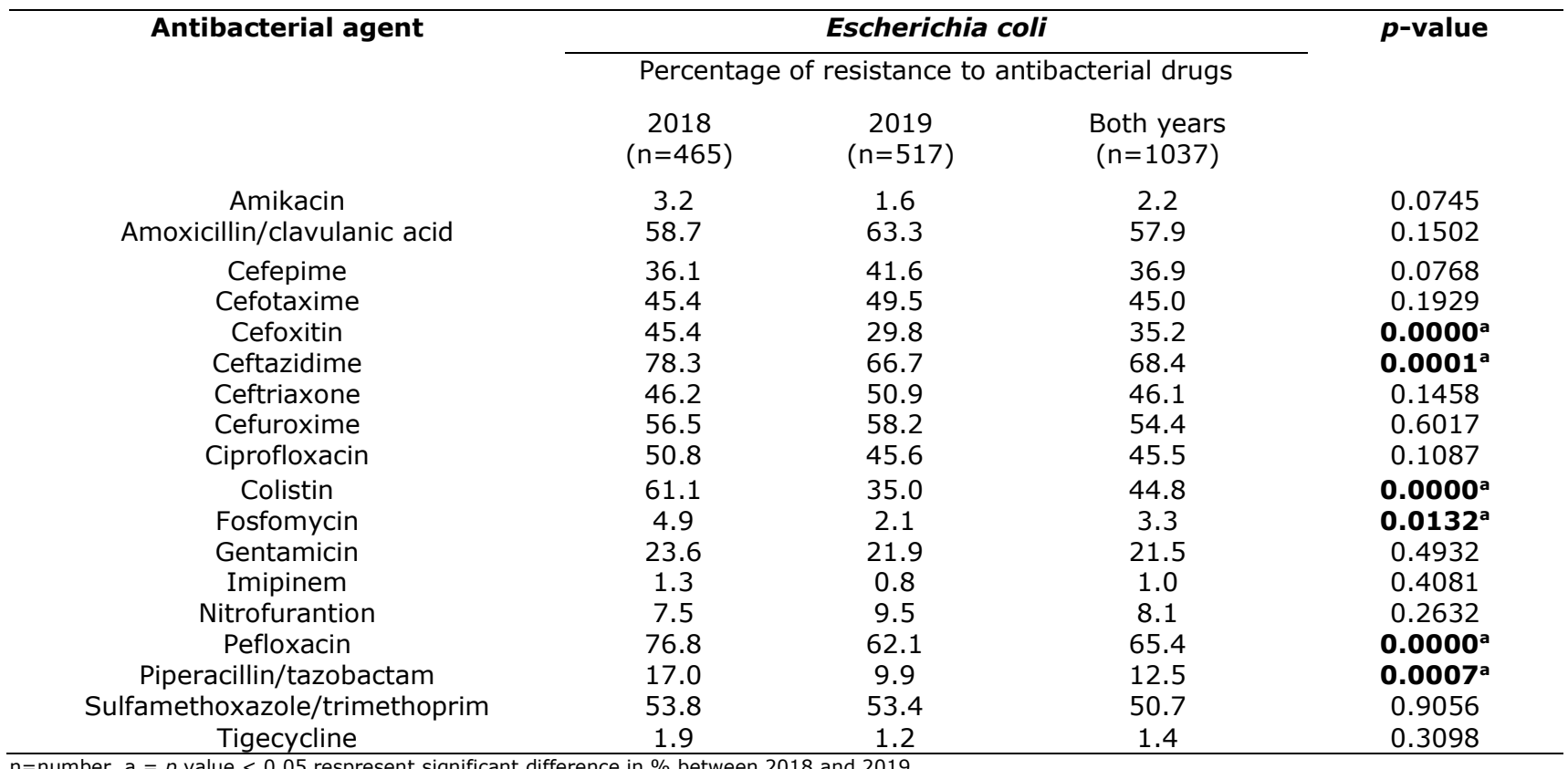


Table 3b: Resistance rate of Gram-negative isolates in 2018 and 2019: Klebsiella pneumoniae

\begin{tabular}{|c|c|c|c|c|}
\hline \multirow[t]{3}{*}{ Antibiotic } & \multicolumn{3}{|c|}{ Klebsiella pneumoniae } & \multirow[t]{3}{*}{$p$-value } \\
\hline & \multicolumn{3}{|c|}{ Percentage of resistance to antibacterial drugs } & \\
\hline & $\begin{array}{c}2018 \\
(n=74)\end{array}$ & $\begin{array}{c}2019 \\
(n=40)\end{array}$ & Both years $(n=114)$ & \\
\hline Amikacin & 1.4 & 0.0 & 0.9 & 0.4602 \\
\hline Amoxicillin/clavulanic acid & 50.0 & 50.0 & 50.0 & 1 \\
\hline Cefepime & 24.3 & 27.5 & 25.4 & 0.7102 \\
\hline Cefotaxime & 37.8 & 32.5 & 36.0 & 0.5708 \\
\hline Cefoxitin & 44.6 & 20.0 & 36.0 & $0.0090^{a}$ \\
\hline Ceftazidim & 83.8 & 62.5 & 76.3 & $0.0107^{a}$ \\
\hline Ceftriaxone & 39.20 & 35.0 & 37.7 & 0.6596 \\
\hline Cefuroxime & 47.3 & 40.0 & 44.7 & 0.4545 \\
\hline Ciprofloxacin & 23.0 & 27.5 & 24.6 & 0.5920 \\
\hline Colistin & 71.6 & 42.5 & 61.4 & $0.0023^{a}$ \\
\hline Fosfomycin & 14.9 & 2.5 & 10.5 & $0.0400^{a}$ \\
\hline Gentamicin & 16.2 & 12.5 & 15.0 & 0.5949 \\
\hline Imipinem & 4.1 & 0.0 & 2.6 & 0.1968 \\
\hline Nitrofurantion & 33.8 & 42.5 & 36.8 & 0.3571 \\
\hline Pefloxacin & 82.4 & 55.0 & 72.8 & $0.0016^{a}$ \\
\hline Piperacillin/tazobactam & 17.6 & 7.5 & 14.0 & 0.1397 \\
\hline Sulfamethoxazole/trimethoprim & 51.3 & 35.0 & 45.6 & 0.0943 \\
\hline Tigecycline & 1.3 & 0.0 & 0.9 & 0.4602 \\
\hline
\end{tabular}

pefloxacin and piperacillin/tazobactam decreased by $34.4 \%, 14.8 \%, 42.7 \%, 56.9 \%, 19.1 \%$ and $41.9 \%$ respectively. Also, E. coli isolates over the 2 years exhibited considerable susceptibility to amikacin, imipenem, and tigecycline. Indeed, less than $3 \%$ of $E$. coli isolates were resistant to each one of these antibiotics, while $8.6 \%$ of the isolates in $2018 / 19$ were resistant to nitrofurantoin.

The results of resistance of $114 \mathrm{~K}$. pneumoniae isolates to 18 different antibiotics assessed for 2018 and 2019 are presented in Table 3b, which shows a significant decrease in 2019 of $K$. pneumoniae resistance to 5 antibiotics; cefoxitin, ceftazidime, colistin, fosfomycin and pefloxacin by $55.1 \%, 25.4 \%, 49.3 \%$, $83.2 \%$ and $33.3 \%$ respectively. Fifty percent of the 114 isolates were resistant to amoxicillin/ clavulanic acid, $76.3 \%$ to ceftazidime, $44.7 \%$ to cefuroxime, $61.4 \%$ to colistin and $72.8 \%$ to pefloxacin. The resistance of the 114 isolates to amikacin, imipenem and tigecycline did not exceed 3\% while between 10 to $14 \%$ were resistant to fosfomycin, gentamicin and piperacillin/tazobactam.

The data on the $99 P$. mirabilis isolates in the study as shown Table $3 c$, showed that $2 \%$ were resistant to imipenem, 5\% to amikacin and piperacillin/tazobactam, and $46 \%$ to amoxicillin/ clavulanic acid. Between 60 and $93 \%$ of these isolates were resistant to ceftazidime, colistin, nitrofurantoin, pefloxacin, sulfamethoxazole/trimethoprim and tigecycline. In 2019, there was a significant decrease in resistance of $P$. mirabilis isolates by $54.6 \%, 18 \%, 65.1 \%, 46.7 \%$, $34 \%$ and $35.9 \%$ respectively to ceftazidime, colistin, fosfomycin, nitrofurantoin, pefloxacin and tigecycline, compared to 2018.

Regarding the resistance of the 93 Enterobacter isolates, as shown in Table 3d, 3\% of the isolates were resistant to amikacin, ertapenem, imipenem and tigecycline. Between 11 and $16 \%$ were resistant to ciprofloxacin, cefepime, gentamicin and piperacillin/tazobactam. Most of the isolates were resistant to amoxicillin/clavulanic acid, cefoxitin, ceftazidime, colistin and pefloxacin, with resistance rate varying between 84 and $98 \%$ of the total isolates. About $250 \%$ more isolates were resistant to piperacillin/tazobactam in 2019 compared to 2018, while in 2019, the resistance of the isolates to colistin and pefloxacin decreased by $26.6 \%$ and $23.4 \%$ respectively, compared to the year 2018 . 
Table 3c: Resistance rate of Gram-negative isolates in 2018 and 2019: Proteus mirabilis

\begin{tabular}{|c|c|c|c|c|}
\hline \multirow[t]{2}{*}{ Antibiotic } & \multicolumn{3}{|c|}{ Proteus mirabilis } & \multirow[t]{2}{*}{ p-value } \\
\hline & $\begin{array}{c}2018 \\
(n=60) \%\end{array}$ & $\begin{array}{c}2019 \\
(n=39) \%\end{array}$ & All years $(n=99) \%$ & \\
\hline Amikacin & 7 & 3 & 5 & 0.3623 \\
\hline Amoxicillin/clavulanic acid & 52 & 38 & 46 & 0.1980 \\
\hline Cefepime & 10 & 10 & 10 & 0.9670 \\
\hline Cefotaxime & 12 & 13 & 12 & 0.8635 \\
\hline Cefoxitin & 28 & 23 & 26 & 0.5614 \\
\hline Ceftazidim & 97 & 44 & 76 & $0.0000^{\mathrm{a}}$ \\
\hline Ceftriaxone & 13 & 13 & 13 & 0.9411 \\
\hline Cefuroxime & 27 & 28 & 27 & 0.8666 \\
\hline Ciprofloxacin & 37 & 31 & 34 & 0.5459 \\
\hline Colistin & 100 & 82 & 93 & $0.0006^{a}$ \\
\hline Fosfomycin & 43 & 15 & 32 & 0.0036 \\
\hline Gentamicin & 30 & 46 & 36 & 0.1025 \\
\hline Imipinem & 3 & 0 & 2 & 0.2493 \\
\hline Nitrofurantion & 92 & 49 & 75 & $0.0000^{a}$ \\
\hline Pefloxacin & 97 & 64 & 84 & $0.0000^{a}$ \\
\hline Piperacillin/tazobactam & 7 & 3 & 5 & 0.3623 \\
\hline Sulfamethoxazole/trimethoprim & 60 & 59 & 60 & 0.9190 \\
\hline Tigecycline & 92 & 59 & 79 & $0.0001^{a}$ \\
\hline
\end{tabular}

Table 3d: Resistance rate of Gram-negative isolates in 2018 and 2019: Enterobacter spp

\begin{tabular}{|c|c|c|c|c|}
\hline \multirow[t]{3}{*}{ Antibiotic } & \multicolumn{3}{|c|}{ Enterobacter spp } & \multirow[t]{3}{*}{$p$-value } \\
\hline & \multicolumn{3}{|c|}{ Percentage of resistance to antibacterial drugs } & \\
\hline & $\begin{array}{c}2018 \\
(n=54)\end{array}$ & $\begin{array}{c}2019 \\
(n=39)\end{array}$ & $\begin{array}{l}\text { Both years } \\
\quad(n=93)\end{array}$ & \\
\hline Amikacin & 4 & 3 & 3 & 0.7588 \\
\hline Amoxicillin/clavulanic acid & 93 & 92 & 92 & 0.9590 \\
\hline Cefepime & 15 & 18 & 16 & 0.6851 \\
\hline Cefotaxime & 22 & 26 & 24 & 0.7018 \\
\hline Cefoxitin & 98 & 97 & 98 & 0.8152 \\
\hline Ceftazidime & 94 & 82 & 89 & 0.0569 \\
\hline Ceftriaxone & 22 & 28 & 25 & 0.5093 \\
\hline Cefuroxime & 63 & 49 & 57 & 0.1709 \\
\hline Ciprofloxacin & 15 & 5 & 11 & 0.1367 \\
\hline Colistin & 94 & 69 & 84 & $0.0011^{a}$ \\
\hline Ertapenem & 2 & 5 & 3 & 0.3775 \\
\hline Gentamicin & 19 & 8 & 14 & 0.1373 \\
\hline Imipinem & 2 & 5 & 3 & 0.3775 \\
\hline Pefloxacin & 94 & 72 & 85 & $0.0025^{a}$ \\
\hline Piperacillin/tazobactam & 6 & 21 & 12 & $0.0275^{a}$ \\
\hline Sulfamethoxazole/trimethoprim & 24 & 28 & 26 & 0.6532 \\
\hline Tigecycline & 6 & 0 & 3 & 0.1345 \\
\hline
\end{tabular}

$\mathrm{n}=$ number, $\mathrm{a}=p$ value $<0.05$ respresent significant difference in \% between 2018 and 2019

Among the $198 P$. aeroginosa isolates (Table $3 e$ ), only $2 \%$ were resistant to colistin and $11 \%$ to amikacin. Between $19 \%$ and $24 \%$ were resistant to cefepime, ceftazidime, cipro- floxacin, gentamicin, imipenem, levofloxacin and piperacillin/tazobactam. In 2019, the decrease of the resistance to amikacin and imipenem was respectively $66.7 \%$ and $65.5 \%$. 
Table 3e: Resistance rates of Gram-negative isolates in 2018 and 2019: Pseudomonas aeruginosa

\begin{tabular}{|c|c|c|c|c|}
\hline \multirow[t]{3}{*}{ Antibiotic } & \multicolumn{3}{|c|}{ Pseudomonas aeroginosa } & \multirow[t]{3}{*}{ p-value } \\
\hline & \multicolumn{3}{|c|}{ Percentage of resistance to antibacterial drugs } & \\
\hline & $\begin{array}{c}2018 \\
(n=105)\end{array}$ & $\begin{array}{c}2019 \\
(n=93)\end{array}$ & $\begin{array}{l}\text { Both years } \\
(n=198)\end{array}$ & \\
\hline Amikacin & 15 & 5 & 11 & $0.0245^{a}$ \\
\hline Cefepime & 21 & 23 & 22 & 0.7815 \\
\hline Ceftazidime & 22 & 16 & 19 & 0.3030 \\
\hline Ciprofloxacin & 25 & 20 & 23 & 0.4678 \\
\hline Colistin & 1 & 2 & 2 & 0.4909 \\
\hline Gentamicin & 19 & 23 & 21 & 0.5403 \\
\hline Imipinem & 29 & 10 & 20 & $0.0008^{a}$ \\
\hline Levofloxacin & 26 & 22 & 24 & 0.4872 \\
\hline Piperacillin/tazobactam & 20 & 20 & 20 & 0.9400 \\
\hline
\end{tabular}

$\mathrm{n}=$ number, $\mathrm{a}=p$ value $<0.05$ respresent significant difference in \% between 2018 and 2019

Table 4a: Resistance rate of Gram-positive bacteria isolates in 2018 and 2019: Enterococcus faecalis

\begin{tabular}{|c|c|c|c|c|}
\hline \multirow[t]{3}{*}{ Antibiotic } & \multicolumn{3}{|c|}{ Enterococcus faecalis } & \multirow[t]{3}{*}{$p$-value } \\
\hline & \multicolumn{3}{|c|}{ Percentage of resistance to antibacterial drugs } & \\
\hline & $\begin{array}{c}2018 \\
(n=29)\end{array}$ & $\begin{array}{c}2019 \\
(n=38)\end{array}$ & $\begin{array}{l}\text { Both years } \\
\quad(n=67)\end{array}$ & \\
\hline Ciprofloxacin & 6.9 & 94.7 & 56.7 & $0.0000^{a}$ \\
\hline $\begin{array}{l}\text { Erythromycin } \\
\text { Gentamicin }\end{array}$ & $\begin{array}{l}65.5 \\
3.5\end{array}$ & $\begin{array}{l}89.5 \\
92.1\end{array}$ & $\begin{array}{l}79.1 \\
53.7\end{array}$ & $\begin{array}{l}0.0168^{a} \\
0.0000^{a}\end{array}$ \\
\hline Linezolid & 0 & 0 & 0 & 1 \\
\hline Teicoplanin & 13.8 & 34.2 & 25.4 & 0.0570 \\
\hline Tigecycline & 0 & 31.6 & 17.9 & $0.0008^{a}$ \\
\hline Vancomycin & 24.1 & 36.8 & 31.3 & 0.2667 \\
\hline
\end{tabular}

$\mathrm{n}=$ number, $\mathrm{a}=p$ value $<0.05$ respresent significant difference in \% between 2018 and 2019

Table 4b: Resistance rate of Gram-positive bacteria isolates in 2018 and 2019: Coagulase Positive Staphylococci

\begin{tabular}{|c|c|c|c|c|}
\hline \multirow[t]{3}{*}{ Antibiotic } & \multicolumn{3}{|c|}{ Coagulase positive staphylococci } & \multirow[t]{3}{*}{ p-value } \\
\hline & \multicolumn{3}{|c|}{ Percentage of resistance to antibacterial drugs } & \\
\hline & $\begin{array}{c}2018 \\
(n=82)\end{array}$ & $\begin{array}{c}2019 \\
(n=63)\end{array}$ & Both years $(n=145)$ & \\
\hline Amoxicillin/clavulanic acid & 30.5 & 25.4 & 28 & 0.4998 \\
\hline Cefoxitin & 87.8 & 46. 0 & 70 & $0.0000^{a}$ \\
\hline Ceftriaxone & 54.9 & 34. 9 & 46 & $0.0168^{a}$ \\
\hline Cefuroxime & 87.8 & 50.8 & 72 & $0.0000^{a}$ \\
\hline Ciprofloxacin & 9.8 & 19.1 & 14 & 0.1077 \\
\hline Clindamycin & 24. 4 & 15.9 & 21 & 0.2094 \\
\hline Erythromycin & 18.3 & 22. 2 & 20 & 0.5576 \\
\hline Linezolid & 0 & 0 & 0 & 1 \\
\hline Ofloxacin & 12. 2 & 19.1 & 15 & 0.2542 \\
\hline Penicillin G & 26. 8 & 58.7 & 41 & $0.0001^{a}$ \\
\hline Sulfamethoxazole/trimethoprim & 9.8 & 6.4 & 8 & 0.4604 \\
\hline Teicoplanin & 0 & 1.6 & 1 & 0.2522 \\
\hline Vancomycin & 23.2 & 7.9 & 17 & $0.0144^{a}$ \\
\hline
\end{tabular}

$\mathrm{n}$ : number, a: $p$ value $<0.05$ represents significant difference in \% between 2018 and 2019 . 
Analysis of the resistance of $67 E$. faecalis isolates to 7 different antibiotics (as shown in Table 4a) clearly revealed a major increase of the resistance of these isolates between 2018 and 2019 to four antibiotics. Compared to the 29 isolates in 2018, the 38 isolates in 2019 showed an increase of their resistance by $1273 \%$ to ciprofloxacin, by $36.6 \%$ to erythromycin, and by $2569.8 \%$ to gentamicin (Table 5). This was added to the fact that in 2018 , none of the isolates was resistant to the tigecycline, compared to $31 \%$ of isolates in 2019 showing resistance to the same antibiotics. None of the isolates in 2018 and 2019 was resistant to linezolid.

The antibiotic resistance patterns of the 145 coagulase positive staphylococci (mainly S. aureus) are summarized in Table 4b, with 82 isolates in 2018 and 63 isolates in 2019. Over these two years, no resistance to linezolid was detected, and only $1 \%$ of patients developed resistance to teicoplanin. Between $8 \%$ and $21 \%$ were resistant to ciprofloxacin, clindamycin, erythromycin, ofloxacin, and sulfamethoxazole/ trimethoprim. Approximately $70 \%, 46 \%$ and $41 \%$ were respectively resistant to cefoxitin, ceftriaxone and penicillin $\mathrm{G}$. The resistant rates in 2019 to amoxicillin/clavulanic acid, cefoxitin, ceftriaxone, cefuroxime and vancomycin decreased by $16.7 \%, 47.6 \%, 36.4 \%, 42.2 \%$ and $65.7 \%$ respectively, compared to 2018 . The resistant rate to penicillin $\mathrm{G}$ however increased by $123 \%$ in 2019 , compared to 2018 (Table 5).

Table 5: Antibiotic resistance rates and trends among bacterial isolates in two Lebanese hospital (2018 and 2019)

\begin{tabular}{|c|c|c|c|c|c|c|c|}
\hline \multirow{2}{*}{ 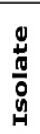 } & \multirow[t]{2}{*}{$\begin{array}{l}\text { Bacterial } \\
\text { species }\end{array}$} & \multicolumn{2}{|c|}{$\begin{array}{l}\text { Lowest and highest resistance rate of total } \\
\text { isolates }\end{array}$} & \multicolumn{4}{|c|}{ Trends in resistance to antibiotics between 2018- 2019} \\
\hline & & $\leq 5 \%$ of resistance & $\geq 60 \%$ of resistance & $\begin{array}{l}\text { Significant decrease of } \\
\text { the resistance to }\end{array}$ & Decrease by: & $\begin{array}{l}\text { Significant increase of } \\
\text { the resistance to }\end{array}$ & Increase by: \\
\hline \multirow{5}{*}{ 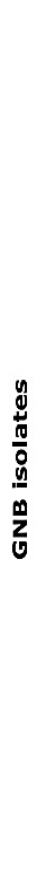 } & E. coli & $\begin{array}{l}\text { Amikacin } \\
\text { Fosfomycin } \\
\text { Imipinem } \\
\text { Tigecycline }\end{array}$ & $\begin{array}{c}\text { Amoxicillin/clavulanic acid } \\
\text { Ceftazidime } \\
\text { Pefloxacin }\end{array}$ & $\begin{array}{c}\text { Cefoxitin } \\
\text { Ceftazidime } \\
\text { Colistin } \\
\text { Fosfomycin } \\
\text { Pefloxacin } \\
\text { Piperacillin/tazobactam }\end{array}$ & $14.7-56.9 \%$ & None & NA \\
\hline & K. pneumoniae & $\begin{array}{l}\text { Amikacin } \\
\text { Imipinem } \\
\text { Tigecycline }\end{array}$ & $\begin{array}{l}\text { Ceftazidime } \\
\text { Colistin } \\
\text { Pefloxacin }\end{array}$ & $\begin{array}{l}\text { Cefoxitin } \\
\text { Ceftazidime } \\
\text { Colistin } \\
\text { Fosfomycin } \\
\text { Pefloxacin }\end{array}$ & $25.4-83.2 \%$ & None & NA \\
\hline & P. mirabilis & $\begin{array}{c}\text { Amikacin } \\
\text { Imipinem } \\
\text { Piperacillin/tazobactam }\end{array}$ & $\begin{array}{c}\text { Ceftazidime } \\
\text { Colistin } \\
\text { Nitrofurantion } \\
\text { Pefloxacin } \\
\text { Sulfamethoxazole/trimethoprim } \\
\text { Tigecycline }\end{array}$ & $\begin{array}{l}\text { Ceftazidime } \\
\text { Colistin } \\
\text { Fosfomycin } \\
\text { Nitrofurantion } \\
\text { Pefloxacin } \\
\text { Tigecycline }\end{array}$ & $18-65.1 \%$ & None & NA \\
\hline & $\begin{array}{l}\text { Enterobacter } \\
\text { spp }\end{array}$ & $\begin{array}{l}\text { Amikacin } \\
\text { Imipinem } \\
\text { Ertapenem } \\
\text { Tigecycline }\end{array}$ & $\begin{array}{c}\text { Amoxicillin/clavulanic acid } \\
\text { Cefoxitin } \\
\text { Ceftazidime } \\
\text { Colistin } \\
\text { Pefloxacin }\end{array}$ & $\begin{array}{l}\text { Colistin } \\
\text { Pefloxacin }\end{array}$ & $23.3-26.6 \%$ & Piperacillin/tazobactam & $250 \%$ \\
\hline & $P$. aeruginosa & Colistin & None & $\begin{array}{l}\text { Amikacin } \\
\text { Imipinem }\end{array}$ & $65.5-66.7 \%$ & None & NA \\
\hline$y_{\substack{0 \\
0}}^{y}$ & E. faecalis & Linezolid & Erythromycin & None & NA & $\begin{array}{l}\text { Ciprofloxacin } \\
\text { Erythromycin } \\
\text { Gentamycin } \\
\text { Tigecycline }\end{array}$ & $36.5-2569 \%$ \\
\hline$\frac{\bar{n}}{\frac{m}{0}}$ & COPS & $\begin{array}{l}\text { Linezolid } \\
\text { Teicoplanin }\end{array}$ & Cefuroxime & $\begin{array}{c}\text { Amoxicillin/clavulanate } \\
\text { Cefoxitin } \\
\text { Ceftriaxone } \\
\text { Cefuroxime } \\
\text { Vancomycin }\end{array}$ & $16.7-65.7 \%$ & Penicillin G & $123 \%$ \\
\hline
\end{tabular}




\section{Discussion:}

In this study, we aimed to compare our findings on antibiotic resistance pattern of $E$. coli, K. pneumoniae, P. mirabilis, Enterobacter $\mathrm{sp}, P$. aeruginosa, E. faecalis, and $S$. aureus isolates from hospitalised patients in Lebanon in 2018 and 2019 with national and international data. The irrational use of antibiotics, easy access, low cost of many antibiotics and absence of an efficient national antimicrobial resistance surveillance system have all contributed to the increase of the resistance of many pathogenic bacterial species to different antibiotics. Our findings however showed a significant decrease (14.8 - 56.9\%) of E. coli resistance in 2019 compared to 2018 against cefoxitin, ceftazidime, colistin, fosfomycin, pefloxacin, and piperacillin/tazobactam, while resistance rate was lowest (less than 3.5\%) against imipinem, amikacin, and tigecycline. This pattern is similar to what was reported between 2011 and 2013 (18), but more than $60 \%$ of our isolates were resistant to amoxicillin/clavulanic acid and ceftazidime, which is significantly higher compared to 2011 and 2013 (which reported 39 and $29 \%$ respectively). In 2015/2016, resistance rate of $E$. coli compared to 2011/2013 in Lebanon increased to most of the tested antibiotics (20). This increase could have been caused by selective pressure of irrational use, promoted by easy access to these antibiotics, which are available over-the-counter in many Lebanese community. This highlights the urgent need for awareness and national educational campaigns to increase the knowledge and ameliorate the attitude and practice towards antibiotic use.

In Gabon, E. coli isolates recovered between 2009 and 2012 were susceptible to ceftriaxone, ciprofloxacin, and gentamicin (21). However, a similar study conducted in Ethiopia between 1990 and 2013 showed that most Gram-negative isolates were relatively resistant to most of the tested antibiotics (22). Between 2012 and 2016 in Nepal (23), 75\% of E. coli isolates from children with urinary tract infection were resistant to cefotaxime, which is higher compared to the $37.2 \%$ reported in our study, but the resistance rates of $E$. coli to gentamicin and amikacin were similar. Compared to a study conducted in Zambia between 2016 and 2018 (24), our E. coli isolates demonstrated higher resistance to ceftazidime but lower resistance to ciprofloxacin. In Iran, E. coli isolates between
2015 and 2016 (25), demonstrated higher resistance to ceftriaxone, ciprofloxacin gentamicin, and imipinem but lower resistance to ceftazidime and amikacin compared to the findings in our study. Smilarly in Yucatan city, in Mexico, between 2016 and 2018 (26), higher resistance rates were seen in $E$. coli isolates compared to the rates reported in our current study.

The $K$. pneumoniae isolates in our study showed low resistance (less than 5\%) to amikacin, fosfomycin, imipinem, and tigecycline and high resistance (more than 60\%) to amoxicillin/clavulanic acid, ceftazidime and pefloxacin. When compared to the year 2018, the resistance rate decreased in 2019 by 25.4 $83.2 \%$ to cefoxitin, ceftazidime, colistin, fosfomycin and pefloxacin. K. pneumoniae isolates in our study showed significantly less resistance to ciprofloxacin, ceftriaxone, and gentamicin compared to $K$. pneumoniae isolates reported between 2009 and 2012 in Gabon (21). In Ethiopia, the resistance rate of $K$. pneumoniae isolates between 1990 and 2013 was considerably lower against cefoxitin compared to the isolates in our current study, but higher resistance to ceftriaxone, amoxicillin/clavulanic acid, ciprofloxacin, gentamicin and trimethoprim/sulfamethoxazole (22). In Iran between the year 2015 and 2016, K. pneumoniae isolates compared to our study showed a lower resistance rate to all the antibiotics tested by Hasani et al., (25) except for ceftazidime. Compared to the findings of Uc-Cachon et al., (26) in Mexico between 2016 and 2018, our isolates showed a significantly lower resistant rates to cefepime, cefuroxime, gentamicin, imipenem, piperacillin/tazobactam and trimethoprim/sulfamethoxazole, but similar resistance rate to ciprofloxacin. According to the WHO and based on the tests performed on 30 isolates per nation, Prestinaci et al., (11) reported that $17.4 \%$ of $K$. pneumoniae isolates Eastern Mediterranean countries were resistant to carbapenems and third generation cephalosporins, while $36 \%$ of isolates from South East Asia and regions of America were resistant, and almost $60 \%$ for the European region.

Our study revealed that amikacin, imipinem, and piperacillin/tazobactam are the antibiotics to which $P$. mirabilis isolates were less resistant to compared to ceftazidime, colistin, nitrofurantion, pefloxacin, sulfamethoxazole/trimethoprim, and tigecycline to which these isolates were most resistant to. A 
significant decrease $(18-65.1 \%)$ in $P$. mirabilis resistance to ceftazidime, colistin, nitrofurantoin, pefloxacin, and tigecycline was reported in our study. This significant decrease could be due to the fact that most of these antibiotics are not accessible in pharmacies but are administrated only in hospitals. Our data showed significantly lower resistance rate to amoxicillin/clavulanic acid, ceftriaxone, ciprofloxacin, gentamicin, and sulfamethoxazole/trimethoprim compared to $P$. mirabilis isolates from the study in Ethiopia (22).

Regarding the resistance patterns of Enterobacter isolates in our study, less than 5\% were resistant to amikacin, imipinem, ertapenem, and tigecycline, but more than $60 \%$ were resistant to amoxicillin/clavulanic acid, cefoxitin, ceftazidime, colistin and pefloxacin. The isolates in 2019 showed a significant decrease $(23.3 \%$ $26.6 \%$ ) in resistance rates to colistin and pefloxacin, but significant increase $(250 \%)$ to piperacillin/tazobactam. Clearly, Enterobacter isolates in the current study showed a lower resistance rate to ciprofloxacin, gentamicin and trimethoprim/sulfamethoxazole but higher resistance rate to ceftriaxone and amoxicillin/clavulanic acid, compared to the isolates in Ethiopian study (22), which could also be explained by the easy access and relative low cost of these two antibiotics in Lebanaon. In Romania, Golli et al., (27) in 2017 reported that Enterobacter isolates showed considerably high resistance rate to cefepime, ceftriaxone, ciprofloxacin, imipenem, but low resistance to ceftazidime.

Our data confirmed that less than $5 \%$ of $P$. aeruginosa isolates were resistant to colistin, and resistance to amikacin, cefepime, ceftazidime, ciprofloxacin, gentamicin, imipinem, levofloxacin, and piperacillin/tazobactam did not exceed $24 \%$ (varied between $11 \%$ to amikacin and $24 \%$ to levofloxacin). There was a decrease in 2019 in the resistance rate to amikacin and imipenem by $65.5 \%$ and $66.7 \%$ compared to 2018. The low incidence of infections caused by $P$. aeroginosa in the Lebanese community could support the significantly lower resistance of this pathogenic bacteria to the tested antibiotics. No significant difference in the pattern of antibiotic resistance of $P$. aeruginosa in our study was observed while comparing the results of the two studies done in Lebanon by Chamoun et al., (18) between 2011 and 2013, and by Moghnieh and colleagues (20) between 2015 and 2016. A fiveyear study conducted in Saudi Arabia between 2013 and 2017 (28) reported high resistance rate in $P$. aeruginosa isolates to $\beta$-lactams, fluoroquinolones and aminoglycosides. The study conducted in India between the 2013 and 2015 reported a similar resistance rate of $P$. aeruginosa to imipenem, comparable to our study. In the study conducted in Iran in 2015 and 2016 (25), P. aeruginosa isolates were more resistant to amikacin, ceftazidime, ciprofloxacin, gentamicin, and levofloxacin, compared to the isolates in our study. As reported by Reta et al., (22) in their retrospective study in Ethiopia between the year 1990 and 2013, P. aeruginosa isolates were significantly more resistant to ciprofloxacin than our isolates, but similar resistance rates were reported to gentamicin. The German study (29) conducted between 2013 and 2018 reported similar resistance rates of $P$. aeruginosa to imipenem, ciprofloxacin and piperacillin/tazobactaman as the isolates in our study, but the German Pseudomonas isolates were less resistant to ceftazidime. In Romania (27), P. aeruginosa isolates in 2017 were more resistant to piperacillin/tazobactaman, ciprofloxacin and ceftazidime compared to our isolates. In Mexico, the resistance rates of $P$. aeruginosa isolates reported between 2016 and 2018 (26) were higher to amikacin, ceftazidime, cefepime, ciprofloxacin, imipenem, gentamicin, levofloxacin, and piperacillin/tazobactam, compared to our isolates.

While analyzing the E. faecalis isolates, our results showed a significant increase $(36.6 \%$ - $2569.8 \%$ ) in the resistance rates of isolates in 2019 to ciprofloxacin, erythromycin, gentamicin, and tigecycline, compared to 2018, which could be explained by the overuse due to wide availability and low cost of macrolides and $\beta$ lactam antibiotics in Lebanon. In Ethiopia, the study by Reta et al., (22) showed lower rates of resistance of $E$. faecalis isolates compared to our isolates while similar resistance rate to erythromycin was reported. In Germany, as shown by Rothe et al., (29), E. faecalis isolates recovered between the year 2013 and 2018 showed no resistance $(0 \%)$ to vancomycin and linezolid while $31.3 \%$ of our tested isolates were resistant to vancomycin though none to linezolid.

Our study also showed that coagulase positive staphylococci CoPS (mostly S. aureus) showed no resistance $(0 \%)$ to linezolid and only $1 \%$ was resistant to teicoplanin. The highest resistance rates were to cefoxitin $(70 \%)$ and cefuroxime $(72 \%)$. This discrepancy in resistance rates could be correlated with overuse of the widely available $\beta$-lactam drugs for treatment of $S$. aureus infections whereas linezolid 
and teicoplanin use is very limited and restricted to hospitalised patients. Cefoxitin is a surrogate phenotypic marker of methicillin resistance in $S$. aureus, which implies that the phenotypic MRSA rate in our study is $70 \%$, a relatively high rate for this pathogen in Lebanon. Approximately $14 \%, 15 \%$ and $17 \%$ of the CoPS isolates were resistant to ciprofloxacin, ofloxacin and vancomycin respectively, $20 \%$ to erythromycin, $21 \%$ to clindamycin, $41 \%$ to penicillin $\mathrm{G}$, and $46 \%$ to ceftriaxone. Between the year 2011 to 2019, the resistance of $S$. aureus isolates to clindamycin, erythromycin and trimethoprim/sulfamethoxazole was relatively stable whereas the rate increased for vancomycin $(18,19,20)$. However, it should be noted that by the CLSI guideline, vancomycin disc diffusion is no longer used to assess phenotypic resistance of clinical $S$. aureus isolates to vancomycin, haven been replaced with vancomycin MIC determination by broth dilution or E-test methods. In Ethiopia, between 1990 and 2013, Reta et al., (22) reported that resistance rate of $S$. aureus isolates was lower for cefoxitin, but higher for amoxicillin/clavulanic acid, erythromycin, trimethoprim/sulfamethoxazole, ceftriaxone and ciprofloxacin. In Iran, between 2015 and 2016 (25), S. aureus isolates showed lower resistance to ceftriaxone compared to the isolates in our study but similar pattern of resistance to ciprofloxacin and amikacin. In the German study by Rothe et al., (29) between 2013 and 2018, 3.3\% of $S$. aureus isolates were resistant to cefuroxime and ceftriaxone compared to $72 \%$ and $46 \%$ in our isolates, and fewer isolates were also resistant to ciprofloxacin compared to our isolates. All S. aureus isolates in the German study were susceptible to linezolid as in our study. However, the resistance rate to vancomycin in the German study was $0 \%$ while the rate was $17 \%$ in our study. In comparing the resistance pattern of $S$. aureus isolates reported by the Greek study conducted between 2010 and 2015 (30) to our current data, it was clear that our isolates were more resistant to cefoxitin, trimethoprim/sulfamethoxazole and vancomycin, while they were less resistant to erythromycin and penicillin $\mathrm{G}$, but similar resistance pattern to teicoplanin and clindamycin.

It has been reported that more than 2.8 million infections and 35,000 deaths caused by antibiotic resistant bacteria and fungi occurs yearly in the United States (31). If no action is taken, drug-resistant infections could cause 10 million deaths each year by 2050 (32). Such infections have serious burden on the economy. Indeed, the cost of AMR across the globe is extremely high though differs between countries (33). Resistance rates are generally higher in low-income countries compared to middle and upper income countries (34).

In Lebanon, the use of antibacterial guidelines should be among the priorities in line with the practice in advanced countries (35). Effective research directed at not only human health sector, but also across animal health and environment sectors, should be prioritised since they are inter-connected (36). This is similar to the action plan adopted by the United States since the year 2015 (37). Global partnerships between industry, researchers and academia are needed to develop new antibiotics such as the European program, New Drugs 4 Bad Bugs (ND4BB) (38), and the Combating AntibioticResistant Bacteria (CARB-X) program, which since its establishment in 2016, is investing in 75 projects around the world and accelerating the global antibacterial innovations (39). A reason to hope of a better future is the fact that approximately 41 new antibiotics (as of March 2017) are in different phases of clinical development aimed at antimicrobial therapy of serious bacterial infections (40).

The present study has some limitations. First, only two hospitals were included in the study, which may not represent the total picture of bacterial AMR in Lebanon. Another limitation is the lack of descriptive details related to the source of the isolates, but we are aiming to assess the multi-drug resistance details among the bacterial isolates in the future. Also, being a retrospective study, we have to rely on the conventional phenotypic methods used for routine bacteria identification and susceptibility tests by the laboratories, which are are not as accurate as genotypic methods. However, our study could motivate the implementation of a national surveillance for antimicrobial resistance in Lebanon.

\section{Conclusion:}

Overuse of antibiotics, which is possible because of easy access to these drugs, is among the major factors underlying emergence and increasing antibiotic resistance in Lebanon. We agree with the 2020 recommendation of Sakr et al., (19) on the need to promote awareness among students, especially in the non-health related majors, and to enact governmental policy that will limit access to antibiotics. 


\section{Acknowledgments:}

The authors acknowledge with thanks Abdul Rahman Shaaban, Adam Hijazi, Arfan Shaaban and Mariam Chams, for their technical assistance (data entry) during the conduct of this study.

\section{Conflict of interest:}

Authors declared no conflict of interest

\section{Contributions of authors:}

AM and TK contributed equally to the study

\section{References:}

1. Bin Zaman, S., Hussain, M. A., Nye, R., Mehta, V., Mamun, K. T., and Hossain, N. A review on antibiotic resistance: alarm bells are ringing. Cureus. 2017; 9: 1403. doi: 10.7759/cureus.1403.

2. Aslam, B., Wang, W., Arshad, M. I., et al. Antibiotic resistance: a rundown of a global crisis. Infect Drug Resist. 2018; 11: 1645-1658.

3. Duval, R. E., Grare, M., and Demoré, B. Fight against antimicrobial resistance: we always need new antibacterials but for right bacteria. Molecules. 2019; 24 (17) : 3152.

doi: $10.3390 /$ molecules 24173152

4. Cassini, A., Hogberg, L. D., Plachouras, D., et al. Attributable deaths and disability-adjusted lifeyears caused by infections with antibiotic-resistant bacteria in the EU and the European Economic Area in 2015: A population-level modelling analysis. Lancet Infect Dis. 2019; 19: 56-66.

5. World Health Organization. WHO Publishes List of Bacteria for Which New Antibiotics are urgentlyNeeded.http://www.who.int/mediacentre/ news/releases/2017/bacteria-antibioticsneeded/fr/

6. O'Neill, J. Review on Antimicrobial Resistance. Antimicrobial Resistance: Tackling a Crisis for the Health and Wealth of Nations. 2014.

7. Laws, M., Shaalan, A., and Rahman, K. M. Antibiotic resistance breakers: Current approaches and future directions. FEMS Microbiol Rev. 2019; 43 (5): 490516.

8. Mouiche, M. M. M., Moffo, F., Akoachere, J. F. T. K., et al. Antimicrobial resistance from a one health perspective in Cameroon: a systematic review and meta-analysis. BMC Publ HIth. 2019; 19: 1135 .

9. Ahmed, I., Rabbi, M. B., and Sultana, S. Antibiotic resistance in Bangladesh: a systematic review. Int J Infect Dis. 2019; 80: 54-61;

doi: https://doi.org/10.1016/j. ijid.2018.12.017

10. Sharma, N., Gupta, A. K., Walia, G., and Bakhshi, R. A retrospective study of antimicrobial resistance pattern of Pseudomonas aeruginosa isolates from urine samples over last three years (20132015). Int J Basic Clin Pharmacol. 2016; 5 (4): 1551-1554.

11. Prestinaci, F., Pezzotti, P., and Pantosti, A. Antimicrobial resistance: a global multifaceted phenomenon. Pathog Glob HIth. 2015; 109 (7): 309-318 doi: $10.1179 / 2047773215 Y .0000000030$.

12. Rawat, D., and Nair, D. Extended-spectrum $\beta$ lactamases in Gram Negative Bacteria. J Glob Infect Dis. 2010; 2 (3): 263-274.
doi:10.4103/0974-777X.68531

13. Moghnieh, R. A., Kanafani, Z. A., Tabaja, H. Z., Sharara, S. L., Awad, L. S., and Kanj, S. S. Epidemiology of common resistant bacterial pathogens in the countries of the Arab League. Lancet Infect Dis. 2018; 18(12).

https://doi.org/10.1016/S1473-3099(18)30414-6.

14. Azimi, T., Maham, S., Fallah, F., Azimi, L., and Gholinejad, Z. Evaluating the antimicrobial resistance patterns among major bacterial pathogens isolated from clinical specimens taken from patients in Mofid Children's Hospital, Tehran, Iran: 2013-2018. Infect Drug Resist. 2019; 12: 2089-2102. doi:10.2147/IDR.S215329.

15. Daoud, Z. Antimicrobial Resistance in the One Health Concept in Lebanon. J Infect Dev Ctries. 2018; 12: 2S. doi: 10.3855/jidc.10201

16. Osman, M., Al Mir, H., Rafei, R., et al. Epidemiology of Antibiotic Resistance in Lebanese Extra-Hospital Settings: an overview. J Glob Antimicrob Resist. 2018; 17:123-129.

17. Araj, G. F., Avedissian, A. Z., Ayyash, N. S., et al. $A$ reflection on bacterial resistance to antimicrobial agents at a major tertiary care center in Lebanon over a decade. J Med Liban. 2012; 60 (3): 125-135.

18. Chamoun, K., Farah, M., Araj, G., et al. Surveillance of antimicrobial resistance in lebanese hospitals: retrospective nationwide compiled data. Int J Infect Dis. 2016; 46: 64-70.

19. Sakr, S., Ghaddar, A., Hamam, B., and Sheet, I. Antibiotic use and resistance: an unprecedented assessment of university students' knowledge, attitude and practices (KAP) in Lebanon. BMC Publ HIth. 2020; 20: 535 .

20. Moghnieh, R., Araj, G. F., Awad, L., et al. A compilation of antimicrobial susceptibility data from a network of 13 Lebanese hospitals reflecting the national situation during 2015-2016. Antimicrob Resist Infect Contr. 2019; 8: 41.

21. Alabi, A. S., Frielinghaus, L., Kaba, H., et al. Retrospective analysis of antimicrobial resistance and bacterial spectrum of infection in Gabon, Central Africa. BMC Infect Dis. 2013; 13 (1): 455.

22. Reta, A., Bitew Kifilie, A., and Mengist, A. Bacterial Infections and Their Antibiotic Resistance Pattern in Ethiopia: A Systematic Review'. Adv Prev Med. 2019; Article ID 4380309. doi:10.1155/2019/4380309.

23. Shah, G., Pokhrel, B., Shah, A. K., Bista, P. B., and Bhattarai, A. Bacterial pathogens and antibiotic resistance patterns in children with urinary tract infection admitted at tertiary hospital in Nepal. J Patan Acad HIth Sci. 2016; 3: 32-36.

24. Chanda, W., Manyepa, M., Chikwanda, E., et al. Evaluation of antibiotic susceptibility patterns of pathogens isolated from routine laboratory specimens at Ndola Teaching Hospital: A retrospective study. PLoS One. 2019; 14 (12): e0226676.

https://doi.org/10.1371/journal.pone.0226676.

25. Hasani, A., Faezi, N. A., Rezaee, M. A., Sheykhsaran, E., Darabi, N., and Leylabadlo, H. E. Determination of Antimicrobial Resistance Patterns in Bloodstream Infections-Isolated Bacteria From a University Tertiary Hospital Patients. Int J Enteric Pathog. 2019; 7 (2): 49-54.

26. Uc-Cachón, A. H., Gracida-Osorno, C., Luna-Chi, I. G., Jiménez-Guillermo, J. G., and Molina-Salinas, G. M. High Prevalence of Antimicrobial Resistance Among Gram-Negative Isolated Bacilli in Intensive Care Units at a Tertiary-Care Hospital in Yucatán Mexico. Medicina. 2019; 55: 588.

27. Golli, A. L., Nițu, F. M., Bălășoiu, M., et al. Microbiological profile and antibiotic resistance pattern of bacterial uropathogens among hospitalized patients. Farmacia. 2019; 67 (1): 167173. 
28. Badger-Emeka, L. I., Emeka, P. M., and Quadri, S. A five-year retrospective study of the antimicrobial susceptibility pattern of Pseudomonas aeruginosa ICU clinical isolates in Al-Ahsa, Saudi Arabia. Biomed Res. 2018; 29 (21): 3856-3862.

29. Rothe, K., Wantia, N., Spinner, C. D., et al. Antimicrobial resistance of bacteraemia in the emergency department of a German university hospital (2013-2018): potential carbapenemsparing empiric treatment options in light of the new EUCAST recommendations. BMC Infect Dis. 2019; 19: 1091.

30. Stefanaki, C., Ieronymaki, A., Matoula, T., et al. Six year retrospective review of hospital data on antimicrobial resistance profile of Staphylococcus aureus isolated from skin infections from a single institution in Greece. Antibiotics (Basel). 2017; 6 (4):39.

31. Centre of Disease Control and Prevention. https://www.cdc.gov/media/releases/2019/p1113antibiotic-resistant.html.

32. World Health Organisation (WHO) https://www.who.int/news/item/29-04-2019-newreport-calls-for-urgent-action-to-avertantimicrobial-resistance-crisis.

33. Utt, E., and Wells, C. The global response to the threat of antimicrobial resistance and the important role of vaccines. Pharm Policy Law. 2016; 18: 179197. doi:10.3233/PPL-160442
34. Klein, E. Y., Tseng, K. K., Pant, S., and Laxminarayan, R. Tracking global trends in the effectiveness of antibiotic therapy using the Drug Resistance Index. BMJ Glob HIth. 2019; 4: e001315. doi:10.1136/ bmjgh-2018-001315.

35. Ong, D. S. Y., Kuyvenhoven, M. M., van Dijk, L., and Verheij, T. J. M. Antibiotics for respiratory, ear and urinary tract disorders and consistency among GPs. J Antimicrob Chemother. 2008; 62: 587-592.

36. Shallcross, L. J., and Davies, D. S. C. Antibiotic overuse: a key driver of antimicrobial resistance. $\mathrm{Br}$ J Gen Pract. 2014; 64: 604-605. doi:10.3399/bjgp14X682561.

37. National action plan for combating antibioticresistant bacteria.

https://obamawhitehouse.archives.gov/sites/defau It/files/docs/national action plan for combating antibotic-resistant bacteria.pdf.

38. Innovative Medicines Initiative. New drugs for bad bugs. http://www.imi.europa.eu/content/nd4bb.

39. Xccelerating global antibacterial innovation. http://www.carb-x.org/.

40. The Pew Charitable Trusts. Antibiotics currently in clinical development.

http://www.pewtrusts.org/ /media/assets/2017/0 5/antibiotics-currently-in-clinical-development-032017.pdf?la $=$ en 